ISSN: 2162-3104 Print/ ISSN: 2166-3750 Online

Volume 7, Issue 3 (2017), pp. 856-875

(C) Journal of International Students

http://jistudents.org/

doi: $10.5281 /$ zenodo. 570038

\title{
Cooperative Activity as Mediation in the Social Adjustment of Chinese International Students
}

\author{
Junqian Ma \\ Monash University, Australia
}

\begin{abstract}
Social adjustment is one of the most difficult and long-lasting challenges for international students who study in a new country. This paper uses a case study of cooperative painting activity conducted in Australian setting, in which two Chinese and three other students from different countries participated, in order to assess the efficiency of cooperative activity in mediating the social adjustment of international students. It argues that three factors determine its mediating function: namely, 1) the relaxing, pushy, and thematic setting, 2) the mediator's role, and 3) communications and interactions. The study provides a new approach to future practices aiming to support the social adjustment of international students.
\end{abstract}

Keywords: cooperative activity, mediating activity, social adjustment

Recently, there is an increasing trend for Chinese students to pursue education abroad. The most popular destinations are English-speaking countries such as the USA, UK, Canada, and Australia (Tian \& Lowe, 2009; Waters \& Brooks, 2011). For instance, in Australia, 34.3\% of the total international students are from China (OECD, 2013). The main driving forces for their choice to study abroad can be the desire to improve their language ability, to understand western culture and to integrate into it, and to receive a high-quality education (Chen \& Zimitat, 2006; Tim \& Geoffrey, 2002). Despite such wishes, large numbers of Chinese international students are still staying within a Chinese community instead of acculturating to the society of the host country. As earlier research reports, Chinese international students prefer to connect with other Chinese students, lack social relations with people from other countries, and consider themselves isolated from the host society (Sawir, Marginson, Deumert, Nyland, \& Ramia, 2008). 
Thus, social adjustment, a process of adapting to and fitting into a host society, establishing and maintaining new social relations, and developing a sense of belonging (Gong \& Fan, 2006; Kağnici, 2012; Kalpidou, Costin, \& Morris, 2011), is one of the most difficult and a longlasting challenges for them. According to existing research, several factors are related to their difficulties in adjusting to a host society, such as language deficiency, cultural differences, and perceived discrimination etc., among which a language barrier is most frequently cited (Russell, Rosenthal, \& Thomson, 2010; Sherry, Thomas, \& Chui, 2010; Yan \& Berliner, 2011; Ye, 2005).

Admittedly, the social adjustment of Chinese international students has been widely researched. However, the majority of these studies merely focus on describing their experiences of and challenges in social adjustment (Robertson, Line, Jones, \& Thomas, 2000; Simpson \& Tan, 2009; Skyrme, 2007; Wan, 2001; Wei et al., 2007), and the possible reasons or factors for difficulties in social adjustment (Andrade, 2006; Lin \& Betz, 2009; C. Wang $\&$ Mallinckrodt, 2006). Less attention has been paid to designing specific approaches to facilitate the process of social adjustment.

The current research, based on Vygotsky's cultural-historical theory and concept of mediation, develops a mediating approach - that of cooperative activity - to supporting Chinese international students to take a first step in adjusting to the multi-cultural context of Australia. The necessary characteristics of cooperative activity are: 1) the task of the activity should be simple and only basic skills are needed; 2 ) the task should be done cooperatively by different people from different countries; 3) there should be no competition in the activity. Although the case study is only conducted for Chinese international students in Australia, it assumes that the findings can also be applied to other international students in other social cultural contexts who face similar difficulties in social adjustment. The role of mediation in social adjustment

\section{THE ROLE OF MEDIATION IN SOCIAL ADJUSTMENT}

This study builds upon Vygotsky's cultural-historical theory and his concept of mediation. It is argued by Veresov (2010, p. 86) that "every higher mental function is a mediated function". Here, higher mental function refers to the improvement of specific psychological functions, or acquiring new methods of reasoning and cultural methods of behavior (Vygotsky, 1994). For Chinese international students, the adjustment to a new society is also a process of mastering new ways of thinking, behaving and communicating, thus it needs to be mediated by certain forms of activity which are referred to as the "mediating activity". Vygotsky (1997b) introduces two types of mediating activity: the use of tools and the use of signs. These draw on 
Hegel's concepts of mediation and on Marx and Engel's notion of tools, where they state that man "makes use of mechanical, physical, chemical properties of things in order to change them into tools to act on other things according to his purpose" (quoted in Vygotsky, 1997b, p. 62). The tools are directed outward and used as a means to change external objects or their nature, while signs, also referred to as "psychological tools", are directed inward and used as a means to master or alter something psychological or internal. In the current research, the painting instruments (e.g. brushes, paper, and pencil) are provided to the participants as tools to draw a picture together, while the language and patterns of communication and interaction are used as signs to connect with other people through which they are changed psychologically.

Vygotsky (1994) provides a diagram (Figure 1) to show how the mediating process takes place. A direct conditional reflexive connection is set up between two points, $\mathrm{A}$ and $\mathrm{B}$. Instead of one associative connection A-B, by utilizing signs, other connections are set up namely, A-X and B-X, which brings the same result, but in a roundabout way (Vygotsky, 1994). In this sense, the connection between $\mathrm{A}$ and $\mathrm{B}$ is not direct, but mediated (Vygotsky, 1997a) by the X, so the unit of mental functions is reorganized and reconstructed.

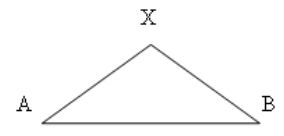

In other words, A represents an individual's current level of a specific developmental aspect, such as the Chinese international student's current level of social adjustment; B refers to the goal an individual seeks to achieve in that aspect, such as Chinese international student fully adjusting to Australian society, establishing sound relations with people around, and developing a sense of belonging in Australia; $X$ is the mediating activity through which an individual with a lower level of development achieves a higher level: for example, Chinese international students with a lower level of social adjustment fully adjusting to Australia through mediating activity. However, in a real situation, the adjustment process from A to B cannot be that simple, and B cannot be achieved merely through one mediating activity (X). This paper develops Vygotsky's general scheme of mediating and establishes a model of the social adjustment process (see Figure 2).

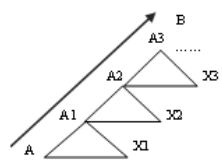

Figure 2: Model of Social of Adjustment Process 
The model indicates that from A to B, an individual needs to achieve stepby-step levels (A1, A2, A3 ...A(n)) through meditation. The study does not argue that Chinese international students can fully adjust to Australia in one mediating activity. Instead, it aims to show that cooperative activity can be one of the mediating activities (e.g. X1, X2, or X (n)) to facilitate their social adjustment even if this is by small steps: e.g. from A to A1, from A1 to A2. The case study: cooperative painting activity

\section{THE CASE STUDY: COOPERATIVE PAINTING ACTIVITY}

A case study was conducted to examine the efficiency of cooperative activity in mediating the social adjustment of Chinese international students and to investigate the core reason for its mediating effect. The current research chose a painting activity as it meets all the characteristics of cooperative activity. First, the painting needs to be finished together, thus it is cooperative. Second, what to paint and how to paint are not decided beforehand and should be discussed during the activity, so it involves communication and connection. Third, painting is a basic skill that everyone possesses and there is no competition, so it is peaceful and stress-free (Daher \& Haz, 2011; Slayton, D'Archer, \& Kaplan, 2010).

The case study aims to find answers to two research questions:

- Can cooperative activity be used as a mediating activity in facilitating the social adjustment of Chinese international students?

- What makes cooperative activity a mediating activity? In order to achieve the research aims, the study was designed as follow.

\section{Participants}

The participants who were the focus of the research were two Chinese international students (Brett and Vicky) from Australian universities: Brett is a 24-year-old master's student and has been in Australia for half a year; Vicky is a 28-year-old $\mathrm{PhD}$ student and has been in Melbourne for one year. They were referred to as the researched participants.

\section{Table 1: Overview of Participants}

\begin{tabular}{lllll}
\hline Types of Participants & Name & Gender & Age & Nationality \\
\hline Researched Participants & Brett & Male & 24 & China \\
& Vicky & Female & 28 & China \\
Other Participants & Wendy & Female & 35 & Indonesia \\
& Sara & Female & 25 & Sri Lanka \\
& Nick & Male & 22 & Australia \\
\hline
\end{tabular}

In order to create a multi-cultural context similar to the social context of Australia, three other student participants from different countries - Wendy, Sara and Nick - were invited, but they are not the focus (See Table 1). None 
of the recruited participants of the research knew each other before the activity.

\section{Procedure}

Gaining consent from the research participants comprises two phases. Firstly, the researcher posted an advertisement on WeChat (a social software which is used by most international Chinese students in Australia) for recruiting one female and one male international Chinese student to participate in the current case study. The participants should meet two criteria: 1) speak Mandarin as first language, and 2) stay in Australia or other English-speaking countries less than 2 years. There are 5 students expressed interest and two of them - Brett and Vicky - who meet the criteria were invited to the study. The second phase involves the recruitment of other participants. They were randomly selected from the Hall of Residence of the University and students who consented to participate were recruited. The researcher was considered an observer, a recorder as well as a 'mediator' within the activity context. In this way the researcher not only was able to investigate the research questions through observing participants' behavior but also was able to play an active role in facilitating the social relations between participants.

All the participants were assembled together in a big room. A large piece of paper, several pencils, erasers, brushes, color pigment and palette were provided and a video recorder was prepared to record the whole process of the painting. There was no direction as to what to draw or how to draw beforehand but participants were required to discuss and decide this during the activity.

\section{Table 2: The Main Focus in Different Stages of Cooperative Painting Activity}

\begin{tabular}{|c|c|c|}
\hline Stage & Content & Main Focus of the Observation \\
\hline $\begin{array}{l}\text { Stage } 1 \\
\text { Self- } \\
\text { introduction }\end{array}$ & $\begin{array}{l}\text { Introduce } \\
\text { themselves to } \\
\text { other participants }\end{array}$ & $\begin{array}{l}\text { The performance and emotions of } \\
\text { researched participants when they } \\
\text { introduce themselves }\end{array}$ \\
\hline $\begin{array}{l}\text { Stage } 2 \\
\text { Discussion } \\
\text { and Decision }\end{array}$ & $\begin{array}{l}\text { Discuss and } \\
\text { decide what to } \\
\text { paint }\end{array}$ & $\begin{array}{l}\text { Whether the researched } \\
\text { participants participate in the } \\
\text { discussion, and how they perform }\end{array}$ \\
\hline $\begin{array}{l}\text { Stage } 3 \\
\text { Painting }\end{array}$ & Paint together & $\begin{array}{l}\text { How the researched participants } \\
\text { collaborated and communicated } \\
\text { with other participants, and what } \\
\text { emotions they experienced }\end{array}$ \\
\hline
\end{tabular}

The cooperative painting activity involves three stages: selfintroduction, discussion and decision, and the painting stage. This whole process was video recorded as the research data. At the beginning, all the 
participants were required to introduce themselves briefly. Before drawing a picture together, every participant was asked to write one word on a piece of paper and the researcher randomly picked one of them. The word which was picked would be the theme of the painting. Under this theme, the participants were required to discuss what to draw. Then the participants began to draw. The researcher had a different focus at different stages (see Table 2).

Additionally, dialogue-based interviews were conducted with the researched participants before and after the activity. It should be noted that the interviews were conducted in Chinese and the transcripts were later translated to English. Two purposes were followed: 1) to identify their attitudes toward the effectiveness of cooperative activity and social adjustment; 2) to understand the reasons for their emotional changes during the activity.

\section{Data Analysis}

The analysis firstly sought to show the researched participants' attitudes before and after the activity to assess the mediating function of cooperative painting in supporting social adjustment. Then the researched participants' emotional changes before, during and after the activity were discussed to further assess the mediating effect of cooperative activity. The emotions were indicated from their behaviors, expressions, and tones. In order to avoid researcher's bias, the video was played for the researched participants after the case study, and asked them to recall and describe their emotional state in a certain moment. In this way, researcher's interpretation can be double checked with researched participants' narrative.

Emotional states are the manifestation of how well an individual can adjust to a new society. First, this is because the process of social adjustment and emotional adjustment are dialectically connected (Fleer, 2006): how an individual understands and deals with the social cultural differences affect his/her emotional experiences, and the changed emotions in turn influence or motivate his/her actions in acculturating to a new social culture environment. In addition, whether an individual experiences a relatively smooth social adjustment or encounters adjustment difficulties can be indicated by his/her emotional state. As is revealed by Thomas (2011), social adjustment problems of international students are often accompanied by negative emotional experiences such as frustration, loneliness, stress, and anger etc. Therefore, by identifying an individual's emotional experience, the process of his/her social adjustment and whether the individual has adjusted to a new society can be disclosed, and thus the first research question can be answered. Based on the above analysis, the study went deeper to explore the main factors in determining the cooperative activity's mediating effect. 
In general, the study adopts Hedegaard (2008)'s three-level interpretation - a common sense level, a situated practice level, and a thematic level - to interpret data. A common sense interpretation is the first statement explicitly made by the researcher to indicate her understanding of researched participants' obvious behavior, performance, and interaction within activity. A situated practice interpretation aims to explicate the emotions and attitudes of the researched people, and the interaction patterns of participants. Finally, the thematic level is closely associated with answering the research questions and achieving the research aims.

\section{FINDINGS}

The findings are reported from three aspects: 1) the researched participants' attitudes toward the cooperative activity and their social adjustment before and after the activity, 2) their emotional changes during the activity and how they reflect on these changes, and 3) the patterns of their interaction with other participants.

\section{Attitudes toward Cooperative Activity and Social Adjustment}

Two results are shown from the interviews with the researched participants at a common sense level (see Table 3.): 1) communication is considered to be the most important factor in social adjustment from Chinese international students' eyes, and language is considered to be the main barrier in their adjusting to Australia; 2) cooperative activity is helpful in helping Chinese international students adjust to Australia mainly because communication takes place.

The first result is supported by previous studies (e.g. Ho, Li, Cooper, \& Holmes, 2007; Mori, 2000; Ye, 2006). The current study also acknowledges that social adjustment has to be achieved via communication. Nevertheless, is it imperfect English that obstructs communication? As is shown in the second result and in the Brett's interview answer (see R4.1 in Table 3), he was not confident in his English ability and "poor English" seemed to be a barrier in communicating with foreigners before, whereas in the cooperative activity, he could actually talk a lot and his English turned out not to be "poor". This indicates that it is not the actual language level that hinders their communication, but the low self-confidence in language ability that blocks social connection. In other words, it is the psychological rather than the language barrier that hinders the social adjustment of Chinese international students.

The psychological barrier, unfortunately, cannot be overcome naturally due to the lack of both the internal "push power" and the external "pull power". The internal "push power" refers to the demands and needs of 
the individual, while the external "pull power" refers to the interventions and invitations that come from influences outside the individual.

Table 3: Researched Participants' Attitudes toward Social Adjustment and Cooperative Activity

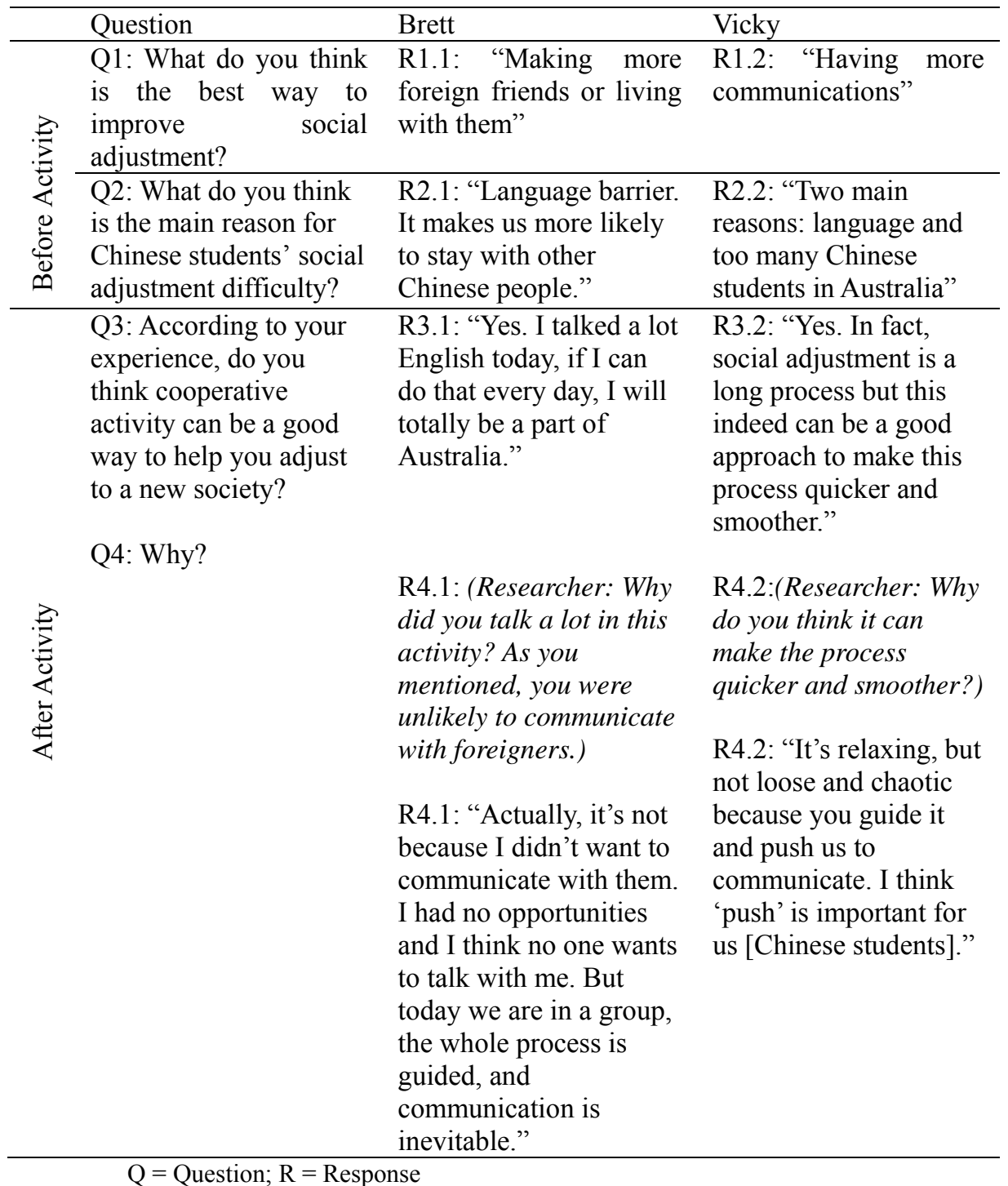

On the one hand, since Chinese international students can study and live well by staying in the Chinese community without communicating with local people or people from other countries due to the large population of Chinese in western countries (e.g. Australia, America and Canada), thus 
their internal "push power" is weak; more seriously, the large Chinese community actually serves as a "negative pull power" to obstruct their communication with the outside. On the other hand, local people and people from other countries seldom take the initiative in communicating with Chinese international students; there are also fewer interventions to urge Chinese international students to connect with the host society, thus the "outside pull power" lacks.

The cooperative activity in the current study serves as the mediating role which offers "outside pull power" to conquer the "negative pull power" of the Chinese community, in order to help Chinese international students overcome psychological barriers in communication, and to pull them towards the social cultural environment of the host country.

\section{Emotional Variations in the Cooperative Activity Process}

In this section, the two researched participants' emotional changes are described to further assess the mediating function of cooperative activity and to explore the reasons underlying these changes.

Emotional changes are mainly observed through changes in an individual's behaviors, facial expression, and tone of voice. These three dimensions are evident in both of the researched participants (see Table 4), suggesting that they have experienced significant emotional changes during the cooperative activity process. To track these emotional variations, this study categorizes the whole observation into three parts (i.e. before, during and after painting); it also classifies the emotional level into excited, relaxed, and tense. It should be clarified that it is categorized in a general sense which does not cover all the subtle emotions researched participant had in the activity. But these three levels can offer a clear picture of how the researched participants changed their emotions. Besides, the judgement of whether the researched participant was excited, relaxed, and tense was not based absolute criteria because different people have different actions and reactions when experiencing certain emotion. Instead, the judgement is based on the researcher's observation and interpretation as well as researched participants' narrative of their emotions when they were watching the videos of the painting activity. The performance of Brett and Vicky are respectively described in Table 4 and are separated into small events (i.e. Brett: 1-12, Vicky: a-i) representing their changing behavior, facial expression, and tone of voice, and what these indicate about their emotional changes. These results show that Brett and Vicky had experienced significantly different emotional changes before and at the beginning of the activity (see Figure 3). Compared with Vicky, Brett's emotional change was more radical and he had also experienced a tense level several times. Then, what made Brett's emotional change so significant? To answer this question, 
events 1 to 7 are analyzed based on the data collected from both the observation and the interview with Brett.

\section{Table 4: Changes in Behavior, Facial Expression, and Tone of Voice}

\begin{tabular}{|c|c|c|}
\hline & Brett & Vicky \\
\hline $\begin{array}{l}\stackrel{0}{0} \\
\stackrel{0}{D} \\
\infty\end{array}$ & $\begin{array}{l}\text { 1. Arrived ten minutes ahead so that he } \\
\text { would not be late (tense) } \\
\text { 2. Chatted with researcher in Chinese } \\
\text { with a gentle voice, and helped the } \\
\text { researcher to prepare before other } \\
\text { participants arrived (relaxed) } \\
\text { 3. Sat quietly, kept playing with the } \\
\text { brushes, and did not look at people } \\
\text { when other participants arrived while } \\
\text { the researcher left to pick up Vicky } \\
\text { (tense) } \\
\text { 4. Stopped playing with the brushes, sat } \\
\text { up straight suddenly, looked at the } \\
\text { researcher and Vicky when they } \\
\text { appeared arriving (excited) } \\
5 \text {. Then sat bowed over and quietly } \\
\text { again (relaxed) }\end{array}$ & $\begin{array}{l}\text { a. (Researcher went to pick up } \\
\text { Vicky. The video recorder kept } \\
\text { recording in the room) Chatted } \\
\text { with researcher and walked briskly } \\
\text { (excited) } \\
\text { b. Looked around when entering } \\
\text { the room, smiled, said hello to } \\
\text { other people (relaxed) } \\
\text { c. Chatted with Wendy when they } \\
\text { found they were from the same } \\
\text { faculty (excited) }\end{array}$ \\
\hline
\end{tabular}

6. Queried his grammar several times, repeated several words, used "er..." often, used hand gestures often, and spoke in a very loud voice when introducing himself (tense)

7. Did not voice his opinion at first, looked at other participants during the

discussion and then drew an earth when Nick suggested it (relaxed)

8. Joked after drawing the earth, and was encouraged by others' laughter (excited)

9. Asked Sara a question about the painting, and discussed animals with Nick and other participants in a humorous and light tone (excited)

10. Introduced his drawing to the researcher when the researcher asked and then discussed the painting with other participants (excited)

11. Helped the researcher clean the table i. Chatted with Wendy and Sara, $\stackrel{g}{g}$ and helped other participants pack up things (relaxed) d. Introduced herself briefly and fluently in a calm voice (relaxed)

e. Voiced her opinion actively in discussion with others (excited)

f. Told other participants what she would draw (excited)

g. Communicated with others while painting, often gave comments, and helped others (excited)

h. Smiled and commented on Brett's penguin as "cute" (excited) and exchanged Facebook addresses (excited) 


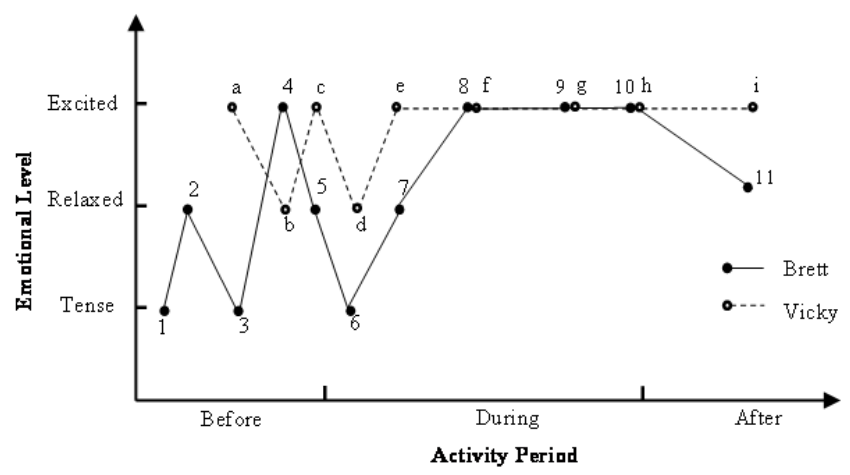

Figure 3: Brett and Vicky: Emotional Changes

Table 1: Brett: Events 1-7: Emotional Levels

\begin{tabular}{|c|c|c|}
\hline Event & $\begin{array}{l}\text { Emotional } \\
\text { Level }\end{array}$ & Reasons given for specific emotional levels \\
\hline & Tense & $\begin{array}{l}\text { 1) seldom attended such an activity before } \\
\text { 2) was afraid of being late and being embarrassed } \\
\text { 3) felt more safe if arrive early }\end{array}$ \\
\hline & Relaxed & $\begin{array}{l}\text { 1) the researcher is Chinese and can speak Chinese } \\
\text { 2) no other participants had arrived }\end{array}$ \\
\hline & Tense & $\begin{array}{l}\text { 1) the researcher left } \\
\text { 2) other participants had come and they were from countries } \\
\text { other than China } \\
\text { 3) had nothing to say and dare not speak with them } \\
\text { 4) did not know what he should do }\end{array}$ \\
\hline & Excited & the researcher and another Chinese participant arrived \\
\hline & Relaxed & felt safe again \\
\hline & Tense & $\begin{array}{l}\text { 1) felt nervous when speaking English in front of people } \\
\text { 2) was not confident with his English and was afraid of } \\
\text { making mistakes }\end{array}$ \\
\hline & Relaxed & $\begin{array}{l}\text { 1) felt safe when listening to other's discussion } \\
\text { 2) knew what he should do } \\
\text { 3) began to engage the activity }\end{array}$ \\
\hline
\end{tabular}

By looking into these reasons, two findings emerge: 1) an individual is emotionally relaxed when he/she feels safe, and emotionally tense when he/she feels unsafe; 2) in this study, the researched participant felt safe when the researcher (who is from the same social cultural background) was present (i.e. events $2,4,5$ ), or when he knew exactly what he should do (i.e. 
event 7); he felt unsafe when the researcher was absent while other participants were present (i.e. event 3 ), or when he was unclear as to what he should do (i.e. event 3). Therefore, the researcher's role is significant in establishing a safe and comfortable environment, and such comfortable environment is the basis for a successful adjustment, without which they might never dare to take the first step. In addition, a theme and specific content are essential for cooperative activity, otherwise for students, such as Brett, who lack confidence, would never know what they should do, would never initiate communication with others, and would never truly participate into the activity.

In fact, Brett represents a vast number of Chinese international students who choose to be passive and silent. Their passivity and silence are not wholly an effect of personality because most of them are considered assertive and active when with other Chinese people, but are mainly caused by a psychological barrier on the one hand, and the lack of a supportive atmosphere on the other (Houghton, Casey, Shaw, \& Murphy, 2013). For these students, a cooperative activity such as that conducted in the present study which involved the researcher's support, and a clear theme and content, can be mediation for adjusting to the host society.

From the observations and the findings on emotional changes, Vicky seemed to be assertive and confident, and seemed to have no difficulties in social adjustment. The interview with Vicky indicates that the positive emotions during the current activity is not due to her assertiveness and confidence in her personality but to the nature of the activity, which is informal and relaxing (unlike formal research activities) on the one hand, directed and "pushy" (unlike chaotic social activities) on the other (see Table 3). Specifically, the nature of the activity provides a comfortable atmosphere, while also offering Chinese international students a supportive guide as well as the power to pull them into communication and cooperation.

Based on the above, three characteristics of activity are necessary to enhance Chinese international students' social adjustment: 1) a safe, relaxing, and comfortable environment and atmosphere, 2) s researcher's supportive 'push' and mediating role, 3 ) a clear theme and content.

\section{The Role of Interactive Connection}

The former section has concluded three reasons for researched participants' emotional experience before and at the beginning of the activity. This section explains why, in the middle part of the activity, both Brett and Vicky reached the "excited" emotional level and that is continued for Vicky and, for a shorter time, for Brett (see Table 4, Brett: 9-11, Vicky: $\mathrm{f}$-h; and Figure 4). The findings show that this was due to the interactive connection with other participants. 
The main distinction between an individual "having interactive connection" and "having non-interactive connection" with others lies in whether such connection is a "unidirectional and closed"

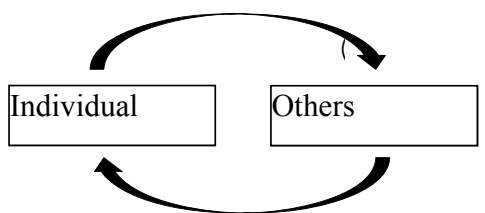

(1) or (2) in Figure 4) or "bidirectional and dialectical" process (both (1) and (2) in Figure 4).

Figure 4: Connections between the individual and the others

Based on this model and taking Brett's case as an example, his monologic self-introduction (see Table 4, event 6) represents the unidirectional process (1) in Figure 4, while his passive listening to the discussion (see Table 4, event 7) represents the unidirectional process (2). Similarly, events 8-10, in which Brett reached his excited level, represent the bidirectional and interactive process (1)-2 depicted in Figure 4. Further information on the interactive connection that took place is spelt out below.

Event 8: After Brett had drawn the earth as Nick suggested, he joked: "Are we going to draw a flag of Japan?"(1) Everybody laughed.(2) Nick added: "good imagination!"(2) "Really? Thank you", responded by Brett with smiling, relaxed, and happy facial expression. (1)

Event 9: Sara helped Brett draw some "continents" on the "earth".(2) Brett pointed to one of them and asked Sara: "Is it the Pacific Ocean?"1 "Yes", she answered and then drew an "Australia" in the "ocean" and said: "And here is Australia".(2) When heard about Australia, Nick was excited and then drew a koala in the "Australia".(2) Brett then added another animal near the koala.(1) Nick asked: "What's this?"(2) "A kangaroo, he likes boxing games and he is playing with this koala", answered Brett.(1) Then, Nick and Brett discussed Australian animals (1) and (2)).

Event 10: The researcher walked around and asked each of them about their painting. (2) Brett pointed to the top of the earth and responded: "This is the bear". (1) Wendy asked: "Why do you draw a bear at that place?" (2) "Because it's a polar bear!" he answered. (1) "Ah...I thought it was a brown bear." replied 
Wendy.(2) Brett continued: "This is a boy who is from Africa and this is the penguin". (1) Everyone in the room laughed including Brett himself because of the funny penguin he had drawn, and Vicky added: "It is so cute!"(2) "Of course, I drew it!" responded Brett. (1)

This is also the case for Vicky. The events (e-h) in which she reached the excited level during the activity all involve interactive connections:

Event e: When the researcher picked one piece of the paper and read: "People."(2) Vicky said: "It was written by me! I think we can draw people from different countries, just like us in the room."(1) This suggestion inspired Nick and he asked: "What about drawing an earth with people around?"(2) "Good idea!" Vicky responded.(1) Then Brett began to draw a big earth.

Event f: Wendy said: "I will draw an Indonesian teacher in my part".(2) This inspired Vicky and she said: "So I will draw a Chinese girl."(1) "Let's do it!” said Wendy.(2)

Event g: When she was drawing her own part, she kept looking at other's work helped them add color and gave positive comment. (1) As the researcher asked what she was drawing, (2) she introduced: "I am drawing a Chinese girl who is traveling around the world and this is the airplane". "Where will the girl travel to?" asked Wendy.(2) "Er...I haven't decided yet." Vicky said.(1) Sara followed, "Maybe Sri Lanka, and welcome to my country."(2) "I haven't been there and I think it's a good choice", responded Vicky. (1)

Event h: Brett introduced: "This is a boy who is from Africa and this is the penguin". (2)Everyone in the room laughed, and Vicky added: "It is so cute!" (1) "Of course, I drew it!" responded by Brett. (2)

The interactive connection was presented as two forms: being initiated by the researched participants, such as event "8", "9", "e", and "g" (see III in Figure 5), and being initiated by the other participants or the researcher but the researched participants have an active respond, such as event "10", "d", "f", "h" (see $\Pi$ in Figure 5). During these types of interaction, researched participants took an active role in the activity instead of responding to the environment passively or silently such as event " 6 " and 
"7" (see I in Figure 5). In this way, they began to consider themselves as the part of the group, and this is the main reason for their "excitement".

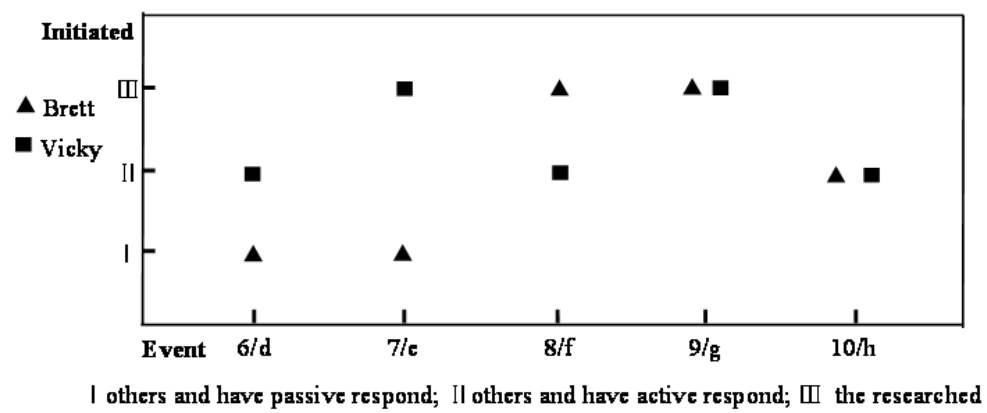

Figure 5: Three types of communications during the activity

Thus, it is essential to purposefully provide opportunities and supports for Chinese international students to have interactive connections with local people or people from other countries. It is true that social adjustment cannot be achieved in one activity, but the experience of such connection can indeed improve their assertiveness and confidence in interacting with people which are necessary in the process of social adjustment.

\section{DISCUSSION}

Inconsistent with previous studies (e.g. Russell et al., 2010; Sherry et al., 2010; Yan \& Berliner, 2011; Ye, 2005), the findings of this research indicate that the most significant barrier for Chinese international students to socially adjust to the host country is not language difficulties, but the psychological barrier. Researched participants' performances, emotional changes, attitudes, and reflections demonstrate the mediating function of cooperative activity in breaking their psychological barrier by connecting them with other people, and by fostering their communications and interactions, which represent a key step in social adjustment process. The results also imply that three essential factors make cooperative activity a mediating activity: 1) a relaxing, pushy, and thematic setting, 2) the researcher's role as a mediator, and 3) the interactive connections.

\section{Relaxing setting with pull powers - a basis for cooperative activity in mediating social adjustment}

Like the results of previous researches (Brown, 2009; Novera, 2004; J. Wang, 2012), this study admits that a friendly, and relaxing atmosphere is necessary in helping international students socially adjust to the host country because only within which they feel safe and behave easily, and only in this 
non-stressful emotional state can they be able to actively interact with others. This point is proved in this study by comparing of Vicky's experience in formal research activities and the experience in the current cooperative painting activity.

However, the study further argues that a relaxing atmosphere alone is not enough. It is because even provided with such relaxing atmosphere, Chinese international students, who lack internal push power, are still unlikely to take initiative in communicating and interacting with local people and people of other countries. Therefore, external pull powers are needed. As is reflected by Vicky, in the chaotic and loose social activities she attended before, she always did nothing because she didn't know what to do; in contrast, in the cooperative painting activity which provides the clear theme, structure and requirements, she engaged, enjoyed, and actively communicated with other participants. And these mentioned clear theme, structure and requirements are actually pull powers. Specifically, the theme and structure pull them to a certain direction so that they would not be "lost" in the setting, and the requirements pull them to proceed in a certain way so that they would be clear of their role and responsibility.

\section{Researcher - a mediator that facilitates the interactions between people}

Some strategies are suggested in previous studies to improve Chinese international students' social adjustment, such as providing mentoring practices (Yeh, Ching, Okubo, \& Luthar, 2007), advisory services (K. Wang et al., 2012) and social supports (Moores \& Popadiuk, 2011). However, these strategies are given in a general way: how to implement, who to implement, and what the operator's role is are not clearly explained. This study argues that these kinds of mediating activities cannot work effectively without a mediator whose role is to intentionally establish a relaxing atmosphere in order to ease the anxiety of Chinese international students, to actively connect people from different countries together, and to constantly pull them into the interactive connections.

In the current study, the researcher's role as a mediator is evident, especially in Brett's case. He felt relaxed when staying with the researcher at the beginning, but went anxious when the other participants were there while the researcher was absent. This suggests that the researcher who shares the same social cultural background and language with Brett can offer him a sense of security. In this sense, the researcher has taken a successful role in forming a relaxing atmosphere. In addition, Brett talked more and more in the cooperative activity as the researcher continually asked participants questions and initiated communications which shows researcher's role in connecting people and pulling Chinese international students into interactions. 


\section{Interactive Connection - a mediating action}

The purpose of establishing a relaxing setting with a pull power and defining the mediator's role was to create the interactive connection between Chinese international students and other people. This connection turns out to be an effective mediating action in helping international students socially adjust to the host country. As is shown in the results, only when the interactive connection took place, the Chinese international students felt emotionally excited and conceived themselves as the part of the community. This indicates that being involved in the interactive connection helps Chinese international students arouse their activeness which free them from their internal shackle, and supports them to gain a sense of belonging within a certain community. This is consistent with the standpoint of socio-cultural and cultural-historical theories that learning and development is mediated by dynamic interaction or interactive connection with others (Herman, 2006; Moschkovich, 2004; Nussbaumer, 2012). In this sense, social adjustment as a part of learning and development process of Chinese international students is definitely mediated by the interactive connection.

\section{CONCLUSION}

The current study uses Vygotsky's concept of mediation as the theoretical framework, based on which the mediating function of cooperative activity in supporting Chinese international student's social adjustment is examined through a case study of painting cooperative activity in an Australian university context. It answers two research questions raised at the beginning. First, although Chinese international students cannot fully adjust to the host country within a short time, cooperative activity can indeed serve as the mediating role and push their social adjustment process a step forward. Second, three factors including safe, pushy, and thematic setting, a mediator, and interactions are key to mediating Chinese international students' social adjustment. In fact, the findings can also be applied to other international students in other social cultural contexts who face the same social adjustment difficulties, such as language difficulty and cultural differences. Therefore, future activities aiming to help international students adjust to the society of host country can follow suit and design a certain cooperative activity characterized with these three essential mediating elements.

At the same time, this study has limitations. Firstly, data are collected from only one case study within one cultural context. The need for more cases and wider investigation are indicated. Besides, on the one hand, it is essential to position researcher as a participant within the research context in order to better understand and interpret the researched participants' emotions, attitudes, and behaviors, etc. On the other hand, due to the deep involvement in the painting activity, researcher's bias could not be fully avoided although the understanding of participants' emotions, 
attitudes, and behaviors were double checked with researched participants themselves.

\section{REFERENCES}

Andrade, M. S. (2006). International students in English-speaking universities: Adjustment factors. Journal of Research in International Education, 5(2), 131154.

Brown, L. (2009). An ethnographic study of the friendship patterns of international students in England: An attempt to recreate home through conational interaction. International Journal of Educational Research, 48(3), 184-193.

Chen, C.-H., \& Zimitat, C. (2006). Understanding Taiwanese students' decisionmaking factors regarding Australian international higher education. International Journal of Educational Management, 20(2), 91-100.

Daher, M., \& Haz, A. (2011). Changing Meanings through Art: A Systematization of a Psychosocial Intervention with Chilean Women in Urban Poverty Situation. American Journal of Community Psychology, 47(3), 322-334.

Fleer, M. (2006). The Cultural Construction of Child Development: Creating Institutional and Cultural Intersubjectivity. International Journal of Early Years Education, 14(2), 127-140.

Gong, Y., \& Fan, J. (2006). Longitudinal examination of the role of goal orientation in cross-cultural adjustment. J. Appl. Psychol., 91(1), 176-184. doi: 10.1037/0021-9010.91.1.176

Hedegaard, M. (2008). Principles for interpreting research protocols. In M. Hedegaard \& M. Fleer (Eds.), Studying children a cultural-historical approach (pp. 46-64). Maidenhead, England: Open University Press.

Herman, D. (2006). Genette Meets Vygotsky: Narrative Embedding and Distributed Intelligence. Language and Literature: Journal of the Poetics and Linguistics Association, 15(4), 357-380.

Ho, E., Li, W., Cooper, J., \& Holmes, P. (2007). The experiences of Chinese international students in New Zealand. New Zealand: University of Waikato

Houghton, C., Casey, D., Shaw, D., \& Murphy, K. (2013). Rigor in qualitative casestudy research. Nurse Researcher, 20(4), 12-17.

Kağnici, D. Y. (2012). The Role of Multicultural Personality in Predicting University Adjustment of International Students in Turkey. International Journal for the Advancement of Counselling, 34(2), 174-184.

Kalpidou, M., Costin, D., \& Morris, J. (2011). The Relationship between Facebook and the Well-Being of Undergraduate College Students. Behav. Soc. Netw., 14(4), 183-189.

Lin, S.-P., \& Betz, N. E. (2009). Factors related to the social self-efficacy of Chinese international students. The Counseling Psychologist, 37(3), 451-471.

Moores, L., \& Popadiuk, N. (2011). Positive aspects of international student transitions: A qualitative inquiry. Journal of College Student Development 52(3), 291-306.

Mori, S. C. (2000). Addressing the mental health concerns of international students. Journal of Counseling and Development, 78(2), 137-144. 
Moschkovich, J. N. (2004). Appropriating Mathematical Practices: A Case Study of Learning to Use and Explore Functions Through Interaction with a Tutor. Educational studies in mathematics, 55(1-3), 49-80.

Novera, I. A. (2004). Indonesian Postgraduate Students Studying in Australia: An Examination of Their Academic, Social and Cultural Experiences. International Education Journal, 4, 475-487.

Nussbaumer, D. (2012). An overview of cultural historical activity theory (CHAT) use in classroom research 2000 to 2009. Educational review, 64(1), 37-55.

OECD. (2013). Education at a glance 2013. OECD indicators: OECD Publishing.

Robertson, M., Line, M., Jones, S., \& Thomas, S. (2000). International Students, Learning Environments and Perceptions: A case study using the Delphi technique. Higher Education Research \& Development, 19(1), 89-102.

Russell, J., Rosenthal, D., \& Thomson, G. (2010). The international student experience: Three styles of adaptation. Higher Education, 60(2), 235-249.

Sawir, E., Marginson, S., Deumert, A., Nyland, C., \& Ramia, G. (2008). Loneliness and international students: An Australian study. Journal of Studies in International Education, 12(2), 148-180.

Sherry, M., Thomas, P., \& Chui, W. H. (2010). International students: A vulnerable student population. Higher education, 60(1), 33-46.

Simpson, K., \& Tan, W. (2009). A home away from home? Chinese student evaluations of an overseas study experience. Journal of Studies in International Education, 13(1), 5-21.

Skyrme, G. (2007). Entering the university: The differentiated experience of two Chinese international students in a New Zealand university. Studies in Higher Education, 32(3), 357-372. doi: 10.1080/03075070701346915

Slayton, S. C., D'Archer, J., \& Kaplan, F. (2010). Outcome Studies on the Efficacy of Art Therapy: A Review of Findings. Art therapy, 27(3), 108-118.

Thomas, G. (2011). A typology for the case study in social science following a review of definition, discourse, and structure. Qualitative Inquiry, 17(6), 511521.

Tian, M., \& Lowe, J. (2009). Existentialist internationalisation and the Chinese student experience in English universities. Compare, 39(5), 659-676.

Tim, M., \& Geoffrey, N. S. (2002). "Push-pull” factors influencing international student destination choice. International Journal of Educational Management, $16(2), 82-90$.

Veresov, N. (2010). Introducing cultural historical theory: main concepts and principles of genetic research methodology. Cultural-historical psychology, 2010(4), 83-90.

Vygotsky, L. S. (1994). The problem of the cultural development of the child. In R. v. d. Veer \& J. Valsinfr (Eds.), The Vygotsky reader (pp. 58-72). Oxford, UK \& Cambridge, USA: Blackwell.

Vygotsky, L. S. (1997a). Analysis of Higher Mental Functions. In R. W. Rieber (Ed.), The Collected Works of L. S. Vygotsky: The History of the Development of Higher Mental Functions (pp. 65-82). Boston, MA Springer.

Vygotsky, L. S. (1997b). Research Method. In R. W. Rieber (Ed.), The Collected Works of L. S. Vygotsky: The History of the Development of Higher Mental Functions (pp. 27-63). Boston, MA Springer. 
Wan, G. (2001). The learning experience of Chinese students in American universities: A cross-cultural perspective. College Student Journal, 35(1), 28.

Wang, C., \& Mallinckrodt, B. (2006). Acculturation, attachment, and psychosocial adjustment of Chinese/Taiwanese international students. Journal of Counseling Psychology, 53(4), 422-433.

Wang, J. (2012). Culturally inclusive practice: A case study of an international student support initiative at an Australian university. Asian Social Science, 8(4), 68-76.

Wang, K., Heppner, P. P., Fu, C., Zhao, R., Li, F., \& Chuang, C. (2012). Profiles of acculturative adjustment patterns among Chinese international students. Journal of Counseling Psychology, 59(3), 424-436.

Waters, J., \& Brooks, R. (2011). 'Vive la Difference?': The 'international' experiences of UK students overseas. Population, Space and Place, 17(5), 567578. doi: 10.1002/psp.613

Wei, M., Liao, K. Y.-H., Wu, T.-F., Heppner, P. P., Mallen, M. J., \& Ku, T.-Y. (2007). Acculturative Stress, Perfectionism, Years in the United States, and Depression among Chinese International Students. Journal of Counseling Psychology, 54(4), 385-394.

Yan, K., \& Berliner, D. C. (2011). Chinese international students in the United States: Demographic trends, motivations, acculturation features and adjustment challenges. Asia Pacific Education Review, 12(2), 173-184.

Ye, J. (2005). Acculturative stress and use of the internet among East Asian international students in the United States. Cyberpsychology and Behavior, 8(2), 154-161.

Ye, J. (2006). An examination of acculturative stress, interpersonal social support, and use of online ethnic social groups among Chinese international students (Vol. 17, pp. 1-20).

Yeh, C. J., Ching, A. M., Okubo, Y., \& Luthar, S. S. (2007). Development of a mentoring program for Chinese immigrant adolescents' cultural adjustment. Adolescence, 42(168), 733.

JUNQIAN MA, PhD candidate. She is currently working as an assistant editor of International Research in Early Childhood Journal and a research assistant. Before starting $\mathrm{PhD}$, She worked in a primary school in China as a class teacher and a Chinese language teacher, after having achieved a bachelor's degree in Education from Jiangsu Normal University, China. Email: Junqian.ma@monash.edu 